\title{
Usefulness of endoscopic band ligation with gel immersion endoscopy for colonic diverticular bleeding and hemorrhoidal bleeding
}
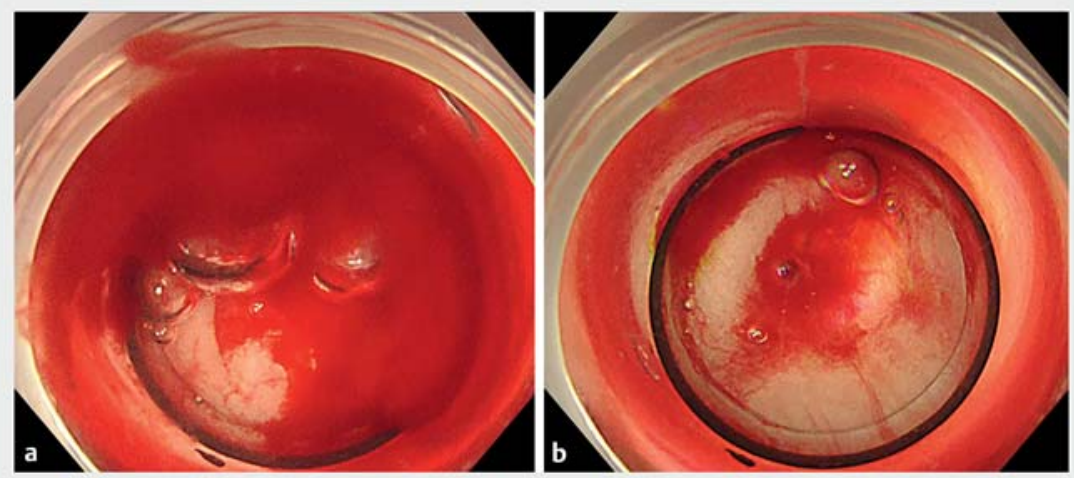

- Fig. 1 a, b Endoscopic band ligation (EBL) with gel immersion endoscopy (GIE), case 1: diverticular bleeding. a Bleeding filled the EBL device, blocking the endoscopic visual field. b Gel injection improved and secured the visual field.
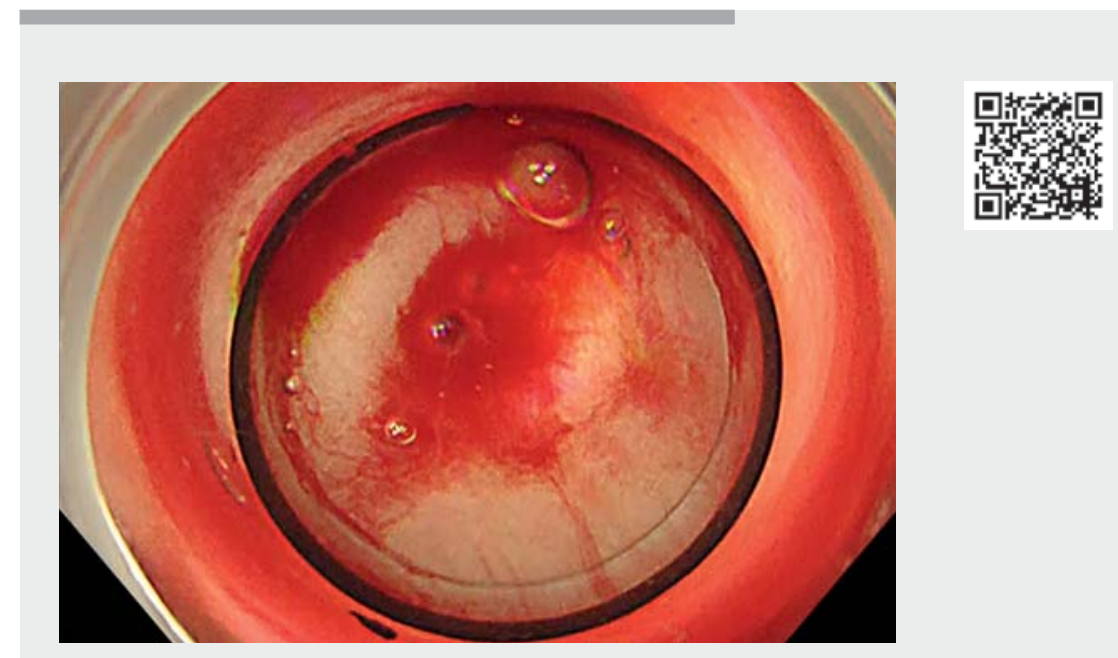

$\checkmark$ Video 1 Successful hemostasis using endoscopic band ligation with gel immersion endoscopy after identifying the bleeding point and securing the visual field to manage diverticular and hemorrhoidal bleeding.

Endoscopic band ligation (EBL) has been recently reported as a useful hemostatic method for colonic diverticular and hemorrhoid bleeding, because of the low rate of rebleeding and high safety. However, the entry of blood into the ligation device attached to the colonoscope disturbs the visual field [1, 2]. Gel immersion endoscopy (GIE) has been recently reported to be useful for clearing the visual field when bleeding occurs during endoscopic resection $[3,4]$. We report two cases in which EBL with GIE was effective for achieving endoscopic hemostasis of bleeding from diverticula and hemorrhoids.

Case 1. A 90-year-old woman complained of fresh bloody stool. Urgent colonoscopy revealed overt and ongoing bleeding from a diverticulum in the

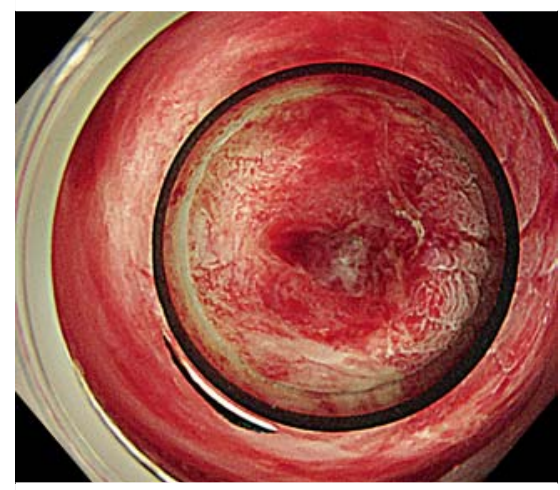

- Fig. 2 Endoscopic band ligation (EBL) with gel immersion endoscopy (GIE), case 2: hemorrhoidal bleeding. The injection of gel improved and secured the endoscopic visual field, which had been blocked when the EBL device filled with blood.

descending colon. Blood entered the EBL device, disturbing the visual field. A marking clip was attached at the opposite side, and endoscopic viewing gel was injected through the forceps opening. The bleeding point was clearly and continuously identified, and hemostasis with EBL was successfully performed (> Fig. 1; Video 1).

Case 2. An 80-year-old man complained of fresh bloody stool. Urgent colonoscopy showed bleeding from hemorrhoids. During an attempt at endoscopic hemostasis with EBL, the bleeding point failed to be detected because of blood entering the EBL device. Injecting gel through the forceps opening helped clear the endoscopic view and detect the bleeding point. Hemostasis with EBL was then successfully performed ( $\triangleright$ Fig.2; $\checkmark$ Video 1).

We report the first two cases in which the combination of EBL and GIE successfully stopped bleeding from a diverticulum and hemorrhoids. This EBL-with-GIE method is considered useful for managing intestinal hemorrhaging, including bleeding from diverticula and hemorrhoids, without special devices or surgery. 


\section{Competing interests}

The authors declare that they have no conflict of interest.

The authors

Yu Kobayashi, Katsuyoshi Ando \akahiro Sasaki, Nobuhiro Ueno, Shin Kashima, Kentaro Moriichi, Mikihiro Fujiya

Gastroenterology and Endoscopy, Division of Metabolism and Biosystemic Science,

Gastroenterology, and Hematology/Oncology, Department of Medicine, Asahikawa Medical University, Hokkaido, Japan

Corresponding author

Katsuyoshi Ando, MD, PhD

Gastroenterology and Endoscopy, Division of Metabolism and Biosystemic Science, Gastroenterology, and Hematology/ Oncology, Department of Medicine, Asahikawa Medical University, 2-1 Midorigaoka-higashi, Asahikawa, Hokkaido 078-8510, Japan

k-ando@asahikawa-med.ac.jp
[1] Higashi R, Kinugasa H, Nakagawa M et al. Endoscopic band ligation for colonic diverticular bleeding. Dig Endosc 2018; 30: 399

[2] Okamoto N, Tominaga N, Sakata Y et al. Lower rebleeding rate after endoscopic band ligation than endoscopic clipping of the same colonic diverticular hemorrhagic lesion: a historical multicenter trial in Saga, Japan. Intern Med 2019; 58: 633-638

[3] Yano T, Nemoto D, Ono K et al. Gel immersion endoscopy: a novel method to secure the visual field during endoscopy in bleeding patients (with videos). Gastrointest Endosc 2016; 83: 809-811

[4] Miura Y, Yano T, Takezawa T et al. Gel immersion endoscopy simplifies hemostasis during endoscopic submucosal dissection using the pocket-creation method. Endoscopy 2018; 50: E294-E295
Bibliography

Endoscopy 2022; 54: E384-E385

DOI 10.1055/a-1550-1913

ISSN 0013-726X

published online 9.8.2021

(C) 2021. Thieme. All rights reserved.

Georg Thieme Verlag KG, Rüdigerstraße 14 , 70469 Stuttgart, Germany

\section{ENDOSCOPY E-VIDEOS}

https://eref.thieme.de/e-videos

口厚回 Endoscopy E-Videos is an open access online section, 回: reporting on interesting cases and new techniques in gastroenterological endoscopy. All papers include a high quality video and all contributions are freely accessible online. Processing charges apply (currently EUR 375), discounts and wavers acc. to HINARI are available.

This section has its own submission website at

https://mc.manuscriptcentral.com/e-videos 